\title{
Genetics in medical practice: The need for ultimate makeover
}

\begin{abstract}
"Been Down So Long It Looks Like Up to Me" was the title of novel in the 1960s, but it could as easily have been the title of a manifesto for medical geneticists. Ever the underdogs of medicine, whether last in line for reimbursement or attention in medical education, medical geneticists may be the rightful heirs to Rodney Dangerfield's position as the chief recipients of "no respect." It doesn't have to be that way. In an era when knowledge of genome structure and function is driving progress in all of medicine, it is no longer necessary to convince medical colleagues or the public that genetics is important. What is necessary is to convince them that the medical genetics community has a vision to guide the integration of genetics into medicine. Several articles in this issue of Genetics in Medicine deal with the challenges of genetics in medical practice, including misperceptions among patients and health providers and the lack of sophistication about genetics among recent medical school graduates. There is an opportunity for medical geneticists to be the Cinderellas of the new era of medical practice. I believe that three words embody the keys to the future: collaboration, responsibility, and quality.
\end{abstract}

Accumulation of money and power and protection of turf are the traditional keys to status and success in medicine. Geneticists have, if anything, been too generous in giving away their time and expertise, leading to a possible conclusion that altruism can be a lethal trait. It is difficult to defend the turf of medical genetics because that turf has a myriad of extensions that border on virtually all other areas of medicine. At the risk of overstretching a geographic metaphor, genetics is more like the ocean than a patch of land, lapping upon the shores of continents and islands everywhere. Geneticists know how to navigate these waters and can exercise dominance over the seas. But this means that they must encourage trade with their colleagues on dry land, and be willing to carry goods from one country to another.

Ability to collaborate will be the coin of the realm in the coming era in medicine and in medical research. Team approaches are necessary to accomplish large research goals using expensive technologies. In health care, people will no longer tolerate the fragmentation of their care into specialty silos where no one sees the whole picture. Geneticists have special skills in risk assessment and prevention of disease. We seem to be constantly defending-even apologizing for-these approaches. They are skills to be proud of. Prevention is the key to health maintenance. That risk assessment could be used to discriminate against individuals does not negate the positive value of the approach. It just argues for the approach being placed in responsible hands. Medical geneticists will probably never be responsible for the care of most patients with com- mon disorders such as asthma or hypertension. But physiciangeneticists, genetic counselors, and laboratory geneticists can be critical members of the care team by performing and interpreting tests, counseling patients, and assisting colleagues in formulation of a care plan. Now is the time to develop these collaborative models and to work with payers to establish mechanisms for reimbursement.

For most of its history as a medical specialty, medical genetics has been long on diagnosis and prevention and short on treatment. With the exception of some inborn errors of metabolism, most disorders considered to be within the purview of medical genetics were viewed as untreatable. Although this may remain the case for some congenital anomalies, the scope of treatment is quickly expanding, for example to include lysosomal storage disorders or some skeletal dysplasias. Increasing knowledge about the pathophysiology of genetic disease is opening opportunities for development of new treatments. We must hope that geneticists have not become so adapted to working in a diagnostic and counseling mode that they have forgotten how to prescribe medications and care for sick patients. If geneticists do not take responsibility for the care of their patients as new treatments are developed, other physicians will certainly do so. Ignoring this opportunity is the surest path toward further marginalization of the discipline. Genetics physicians must accept their responsibility as doctors if they are to be valued and respected by their colleagues.

The third pillar upon which the future of medical genetics rests is that of quality of care. As patients become empowered with knowledge and information, they are coming to recognize that not all physicians are equal. Some do a better job than others; some make fewer mistakes; some are more accessible and engaged; some communicate better. As the tools of medical diagnosis and treatment become more powerful, there will be a corresponding expectation that patients will have access to the best quality of care, not the average quality. Successful implementation of prevention strategies, avoidance of side effects by tailoring drug dosage to an individual's pharmacogenetic profile, and stratification of disease using genomic tools will increasingly set the standard by which successful outcomes are judged. Geneticists can leapfrog over any discussion of "turf" by invoking models based on the best outcomes and will thereby be leaders in the development of a new approach to medical practice.

The environment of medicine is changing, maybe slowly and sometimes imperceptibly, but the change will be radical. Geneticists should understand better than anyone the importance of adaptation to change as the key to survival. It may be that a discipline that was ill suited to thrive in an era of the 
individual entrepreneurial approach to medicine will be ideally adapted to a new era in which teams of providers work together to maintain health and treat disease with an eye on quality of outcomes. The six articles in this issue of Genetics in Medicine provide a glimpse of this new environment, and some of the issues raised by the broad application of genetics in medicine. The medical genetics community is faced with a major oppor- tunity in this new era to be leaders in what promises to be a gradual but radical restructuring of medical practice.

Bruce R. Korf, MD, PhD Department of Genetics University of Alabama at Birmingham Birmingham, Alabama 